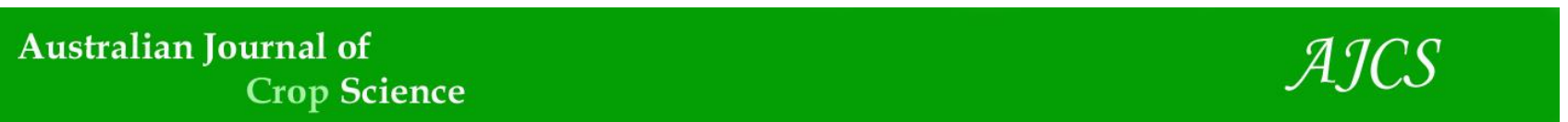

AJCS 15(12):1485-1491 (2021)

ISSN:1835-2707

doi: 10.21475/ajcs.21.15.12.p3429

\title{
Assessment of yield and quality of quinoa accessions grown in Ferralsols following seasonal difference
}

\section{Nguyen Van Minh ${ }^{1}$ and Tinh Van Nguyen ${ }^{2 *}$}

\author{
${ }^{1}$ Faculty of Agriculture and Forestry, Tay Nguyen University, 567 Le Duan Street, Dak Lak province 63000, Vietnam \\ ${ }^{2}$ Department of Basic Science, Buon Ma Thuot University, Dak Lak province 63000, Vietnam
}

\author{
*Corresponding author: nvtinh@bmtvietnam.com
}

\begin{abstract}
The quinoa accession varieties have been cultivated in Vietnam in recent decades. The initial results indicate that these varieties have well adapted to Vietnam's climate, even better than some of their mother areas. However, further evaluation of the impact of the seasonal region on quinoa growth and development is necessary for a tropical country like Vietnam. Therefore, this study aimed to analyze the yield and quality of quinoa accession varieties planted on Ferralsolsl in the Dak Lak province of Vietnam in three distinct seasons. Ten quinoa accession varieties include Leucan Boldo, Riobamba, 27 - 6R, EDK - 4, 59 - ALC, ISLUGA, Atlas, Cahuil, Moradas and Haiwan were examined. Field experiments were conducted based on the Randomized Complete Block Design (RCBD) in triplicated repeat. Various plant agronomical traits including plant height, branch number, the total number of the main bunch, length of the bunch, number of grains per bunch, grains weight, as well as the contents of protein, and starch were investigated. Finally, the biological and practical productivity of ten quinoa accessions was determined. In general, the obtained results showed that the quinoa varieties are grown from January to April 2020 (Season 1) had higher quality and yield than those grown in other seasons. Collectively, the variety Atlas showed the highest-quality indexes including agronomical traits such as approximately 37 branches per plant or its bunch length was around $27 \mathrm{~cm}$, and its practical productivity was 22.2 quintals per hectare follow by the Moradas, Cahui, and Haiwan varieties. Taken together, our data indicated that the correlation of the seasonal factor in Dak Lak province of Vietnam is different for each quinoa variety.
\end{abstract}

Keywords: Ferralsols, Quality, Quinoa Accessions, Seasonal Factor, Vietnam, Yield.

Abbreviations: ANOVA_Analysis of variance; P_Probability; FAO_Food and Agriculture Organization; SD_Standard Division.

\section{Introduction}

Quinoa (Chenopodium quinoa Willd.) is a type of chenopod with high nutritional value. It is a pseudo-cereal food cultivated in several Andean countries of Latin America. Although quinoa is considered the oldest crop in the world with a history of cultivation dating back about 10,000 years, it has only received great research attention in the last 20 years. Despite the fact that quinoa is native to temperate regions, quinoa can be cultivated well in various tropical regions (Aguilar et al., 2003). In cultivation strategy to gain high quality and yield, the selection of varieties suitable for the conditions of different ecological regions is very important. Analyzing quinoa varieties always bases on their specific adaptive characteristics such as plant growth, development, yield, and quality. In nature, environmental factors can affect genetic traits, thus different varieties are always brought distinctive traits to adapt to specific regions (Aguilar et al., 2003).

Quinoa was first planted in Vietnam in 1986. The HV1 is the first variety cultivated in some Northern provinces of Vietnam with the yield ranging from 14.0 to 20.6 quintals per hectare (Vu and Vu, 1993; Lyakhovkin and Tran, 1994; Trinh, 2001). Up to now, the variety HV1 has been selected to grow in many regions in Vietnam. According to Bertero et al. (2004), quinoa is well adapted to climate and soil conditions in Vietnam, giving even higher yields than some of their original regions.
With the aim of developing quinoa as a commercial crop, the selection of new varieties as well as research on suitable cultivation techniques, especially planting density is an important technical measure contributing to the increase of crop yield.

Effects of climate change on crop yield are attracting great attention from farmers, government officials, and scientists. Vietnam is one of the countries most affected by global climate change. According to the analysis of ADB (2013), Vietnam is in group 13 of countries with the largest agricultural production area affected by drought in the next 30 years. Global climate change caused sea levels to rise by $2.15 \mathrm{~mm}$ per year; while the dry season is prolonged and saline intrusion is increasing (Tran and Nguyen, 2013). As the survey of Tran and $\mathrm{Vu}$ (2013), if the sea level continues to rise by one meter, Vietnam will be lost $50 \%$ of its arable land compared to the present, and the coefficient of land use will also decrease.

According to the statistics of the Vietnam Ministry of Agriculture and Rural Development in 2017, drought and water shortage are occurred throughout the Central Highlands region. Whereby, Dak Lak province was lost 56,138 hectares of coffee caused by the drought. Interestingly, quinoa is a plant that can withstand adverse conditions such as acidic soil, drought, salinity, and high latitudes (Ruiz-carrasco et al., 2011). In the 
face of such an urgent situation, research to convert a new plant variety (Quinoa) suitable for areas with severe difficult conditions is necessary and urgent to contribute to ensure the food security.

Quinoa can grow and develop well on almost all soil types such as nutrient-poor, arid, rocky, hills, acidic, alkaline, hummus, saline soils, coastal sandy soil or withstand a wide $\mathrm{pH}$ range (4.8 to 8.5). Similarly, trials conducted in Dak Lak province, Vietnam in 2017 indicated that quinoa accessions are well adapted to drought and salinity conditions.

Central Highland Vietnam includes five inland provinces. Almost this entire region is mountainous, surrounded by high mountain ranges and massifs, especially the southern part of Truong Son Mountain Range. Central Highlands can be divided into three sub-regions of terrain and climate, including highlands in the northern (Kon Tum and Gia Lai provinces), highlands in the central (Dak Lak and Dak Nong provinces), and highlands in the southern (Lam Dong province). Central Highlands has a lower altitude and higher temperature than other sub-regions. Influenced by equatorial climate, the annual average temperature is about $25^{\circ} \mathrm{C}$ with moderate climate all year round. The climate in Central Highlands Vietnam has two distinct seasons as dry season and rainy season. Located in the tropical savanna, the climate in Central Highland Vietnam is divided into two seasons: the rainy season from May to October, and the dry season from November to April. During this period, March and April witness the hottest and driest weather. As the difference in altitude, the climate in about 500-meter high plateau is relatively cool and rainy, while in the plateau of over 1000 meters (Da Lat city) is cool all year round, featuring alpine climate. Thus, this region has ideal weather in comparison to the general weather in Vietnam.

Basalt red soil (Ferralsols) is the predominant soil type in the Central Highlands of Vietnam, accounting for more than $24 \%$ (about 1.45 million ha) of the total natural land area of this region. Ferralsols is an igneous rock formed by the eruption of a layer of material deep in the earth's crust. According to the process of volcanic eruptions, these layers of material are poured out to the earth's surface and cooled to form a basaltic red soil layer in some regions of the world. According to the results of the soil classification study of Van Wambeke, (1992), the red soil group is divided into 3 colors including red-brown, yellow-brown and yellow-red humus. The general characteristics of this soil group are acidic soil, low base saturation, relatively thick soil layer, clay minerals are mainly kaolinite, relatively stable granules and fast drainage. The special feature of this soil is the small slope, thick, porous soil layer, rich in nutrients (Van Wambeke, 1992).

In this study, we assessed 10 selected quinoa accession varieties including Leucan Boldo, Riobamba, 27 - 6R, EDK - 4, 59 - ALC, ISLUGA, Atlas, Cahuil, Moradas and Haiwan grown on Ferralsols in Buon Ma Thuot city, Dak Lak province. The experiments were carried out in 3 seasons in the year 2020. We analyzed the yield, quality of quinoa accession varieties to find the suitable varieties for Ferralsols planting conditions. As the result, season 1 (whole dry season) is more suitable for quinoa accessions growth and development. The Atlas variety showed the highest practical yield follow by the Moradas, Cahui, and Haiwan varieties.

\section{Results and Discussions}

Several indicators of growth and development of quinoa accessions

Plant height is one of the important indicators reflecting the growth and development of quinoa (García et al., 2020). Plant height is usually characteristic of each variety. However, it is significantly influenced by external conditions and cultivation techniques such as season, soil type, density or fertilizer compose (Wang et al., 2020). The plant height of ten quinoa accession varieties grown on Ferralsols in Dak Lak province recorded in three different seasons was shown in Figure 1. Different quinoa varieties have an effect on plant height which was analyzed after 75 days of planting (Fig. 1A). The results showed the final plant height of the experimental varieties in our study was over $120 \mathrm{~cm}$, much higher than the height obtained from the quinoa variety HV1 in the study of Trinh, (2001) which was around $79 \mathrm{~cm}$. This difference can be attributed to the quinoa varieties in the two experiments being different and grown in different locations with different climatic conditions. In detail, the Atlas showed the lowest plant height, while the Moradas showed the highest plant height. In a comparison of seasonal effectiveness, the plant height of all quinoa varieties planted in season 1 was significantly higher than in season 3 and season 2 (Fig. 1A). This result indicated that quinoa plant height was affected by seasonal factors and soil type.

The ability of quinoa branching is highly is influenced not only effect by genetics but also by various external factors such as nutrition, density, temperature, or water regime (Hinojosa et al., 2018; Granado-Rodríguez et al., 2021). In this study, we aimed to be proactive in technical care measurements to control the branching process as desired, besides limitation ineffective cotton and effective cotton concentration. In 75 days after planting, quinoa accessions do not increase the number of branches, because the plant begins to enter the seeding stage, and nutrients gather in the seeds. The results of number quinoa branching in three distinct seasons were shown in Figure 1B. The quinoa varieties grown on Ferralsols had a difference in the number of branches per plant. The average number of branches was approximately 18 to 30 . Among the three seasons, the number of branches of quinoa accessions in season 1 was higher than that in other seasons. Season 2 showed lower quinoa accession branching than others (Fig. 1B). It was found that the lowest branch was the Lucas boldo with approximately 18 in season 2 and the highest branch was approximately 30 of the Atlas in season 1 (Fig. 1B). These results indicated that the quinoa accessions cultivated in the Ferralsols depend on seasonal factors.

The amount of branch is of the critical indicators for plant reproductive ability. The quantity and quality of the quinoa branches are due to genetic and environmental factors (Hinojosa et al., 2018; Granado-Rodríguez et al., 2021). In the study, we analyzed the quality of branches on individual quinoa accession plants. The experimental plots were surveyed on 100 plants for each measurement and repeated three times. The amount and length of 10 quinoa accession varieties which grow in 3 different seasons after 75 days of planting were recorded. As shown in Figure 2A, the average total number of branches on an individual quinoa accession plant was ranging from 21 to 34 . The quinoa accessions growth in season 1 showed a higher number of branches than those in other seasons, with a statistically significant difference of $95 \%$. The Atlas, Moradas, Cahui, and Haiwan had a higher number of branches followed by the 27-6R, EPK-4, and 59-ALC. The Lucas boldo and Riobambar exhibited the lowest number of branches per plant. In detail, the Atlat which was cultivated in season 1 gained approximately 37 branches per plant. On the 
Table 1. Monthly average climatic data on rainfall, temperature, and relative humidity in the research location.

\begin{tabular}{|c|c|c|c|c|c|}
\hline Month & Temperature $\left({ }^{0} \mathrm{C}\right)$ & Rainfall (mm) & RH (\%) & NHSPD (hour) & NRDPM (Day) \\
\hline 1 & 21.5 & 5.8 & 79.6 & 249.4 & 2.0 \\
\hline 2 & 21.7 & 5.5 & 77.8 & 213.3 & 2.0 \\
\hline 3 & 25.4 & 5.9 & 72.4 & 287.9 & 1.6 \\
\hline 4 & 25.8 & 213.4 & 74.6 & 277.6 & 4.0 \\
\hline 5 & 25.6 & 247.6 & 82.2 & 252.3 & 6.0 \\
\hline 6 & 25.3 & 310.2 & 85.0 & 215.6 & 19.8 \\
\hline 7 & 25.9 & 213.8 & 84.0 & 194.1 & 20.7 \\
\hline 8 & 26.2 & 250.0 & 87.0 & 192.5 & 17.5 \\
\hline 9 & 25.0 & 289.2 & 86.2 & 174.6 & 23.0 \\
\hline 10 & 23.8 & 396.0 & 87.4 & 104.9 & 24.0 \\
\hline 11 & 25.5 & 201.3 & 74.7 & 218.6 & 7.0 \\
\hline 12 & 27.6 & 30.6 & 73.4 & 265.7 & 4.0 \\
\hline Average & 24.9 & 180.8 & 80.4 & 220.5 & 9.5 \\
\hline
\end{tabular}

(RH: Relative humidity; NHSPD: Number of hours of sunshine per day; NRDPM: Number of rainy day per month)

(A)

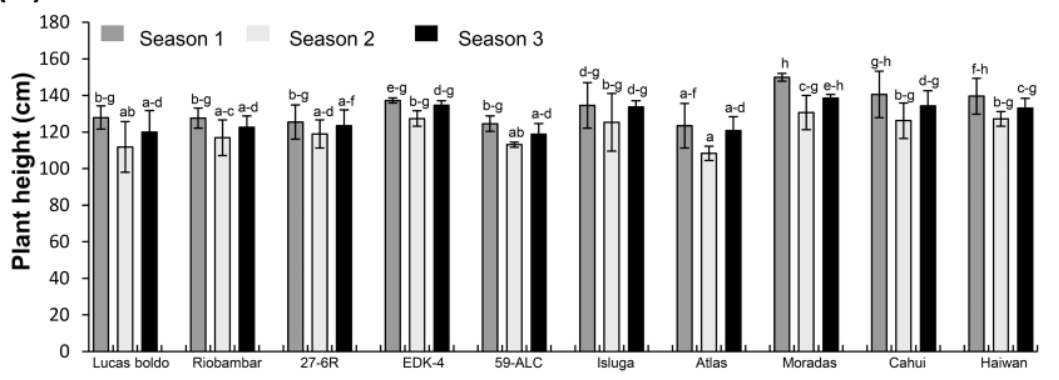

(B)



Fig 1. Comparison of plant height (A) and total of number of branches (B) of ten quinoa accession varieties recorded after 75 days of planting in three different seasons. Bars represent mean values $( \pm S D)$ of three independent tests. Different letters above bars indicate the statistically significant difference (ANOVA, $P<0.05$ ).

Table 2. The origin and main characteristics of ten quinoa accessions (Nguyen and Nguyen, 2019).

\begin{tabular}{|c|c|c|c|c|}
\hline \multirow{2}{*}{ No } & \multirow[t]{2}{*}{ Variety } & \multirow{2}{*}{ Provenance } & \multicolumn{2}{|c|}{ Main characteristics } \\
\hline & & & Growth time (day) & Stress resistance \\
\hline 1 & Leucan Boldo & Argentina & $90-110$ & Drought \\
\hline 2 & Riobamba & Nederland & $90-110$ & Drought \\
\hline 3 & $27-6 R$ & Nederland & $85-110$ & Drought \\
\hline 4 & EDK - 4 & Nederland & $85-110$ & Drought \\
\hline 5 & $59-\mathrm{ALC}$ & Argentina & $85-110$ & Drought \\
\hline 6 & ISLUGA & Chile & $85-110$ & Drought \\
\hline 7 & Atlas & Nederland & $90-120$ & Drought \\
\hline 8 & Cahuil & Chile & $85-110$ & Drought \\
\hline 9 & Moradas & Chile & $85-110$ & Drought \\
\hline 10 & Haiwan & Argentina & $85-110$ & Drought \\
\hline
\end{tabular}



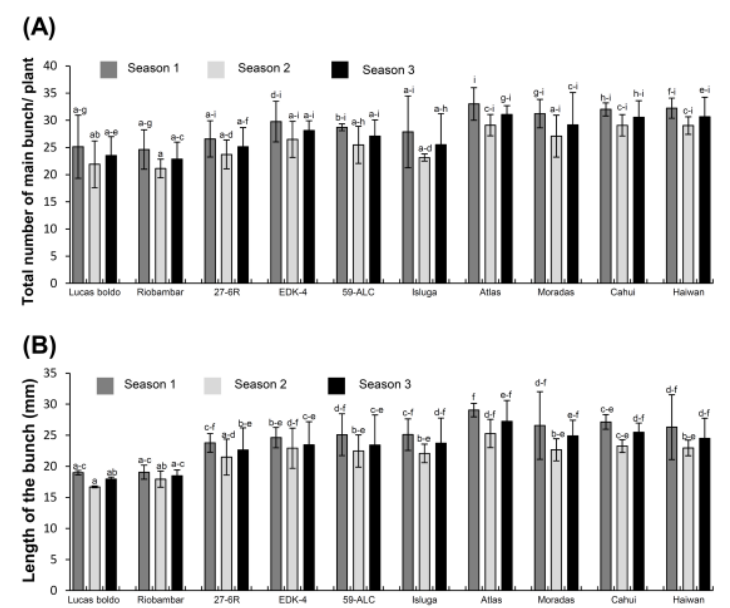

Fig 2. Total number of the main bunch per plant (A) and length of the bunch (B) of ten quinoa accession varieties recorded after 75 days of planting in three different seasons. Bars represent mean values $( \pm S D)$ of three independent tests. Different letters above bars indicate the statistically significant difference (ANOVA, $P<0.05$ ).

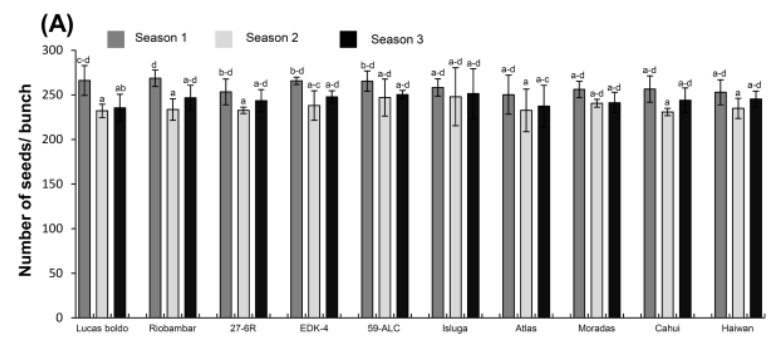

(B)

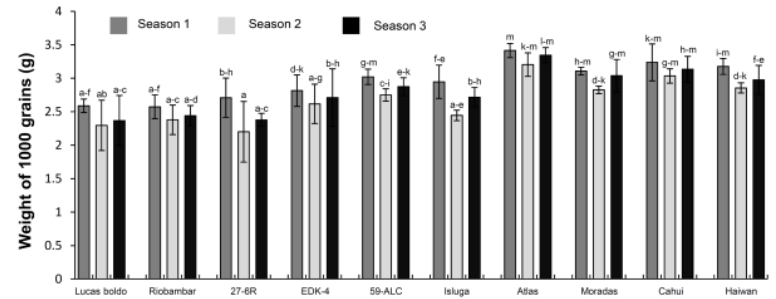

Fig 3. Comparison number of seeds per bunch (A) and the weight of 1000 grains (B) of ten quinoa accession varieties recorded after 75 days of planting in three different seasons. Bars represent mean values ( \pm SD) of three independent tests. Different letters above bars indicate the statistically significant difference (ANOVA, $P<0.05$ ).

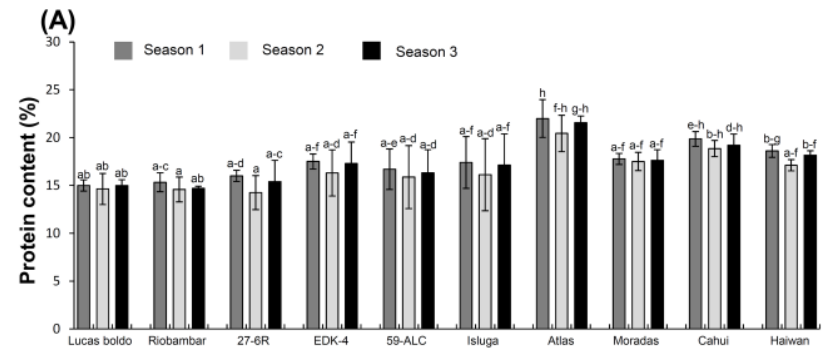

(B)

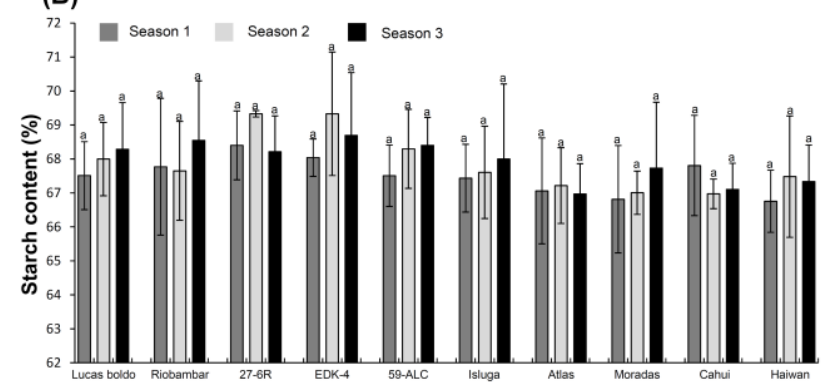

Fig 4. Protein content $(A)$ and starch content $(B)$ of ten quinoa accession varieties planted in three different seasons. Bars represent mean values $( \pm$ SD) of three independent tests. Different letters above bars indicate the statistically significant difference (ANOVA, $P$ $<0.05)$. 


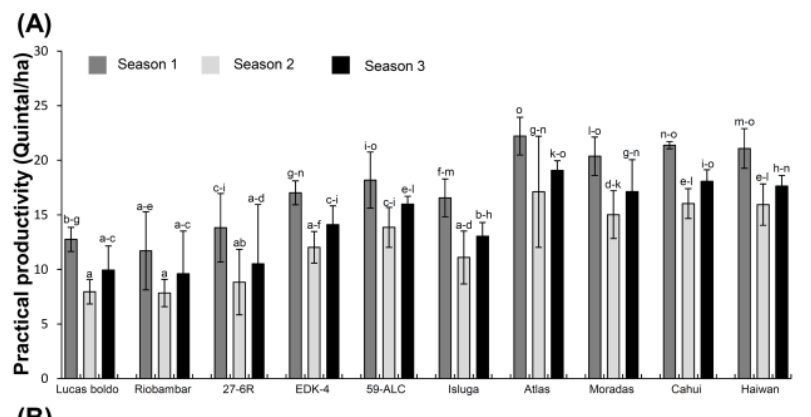

(B)

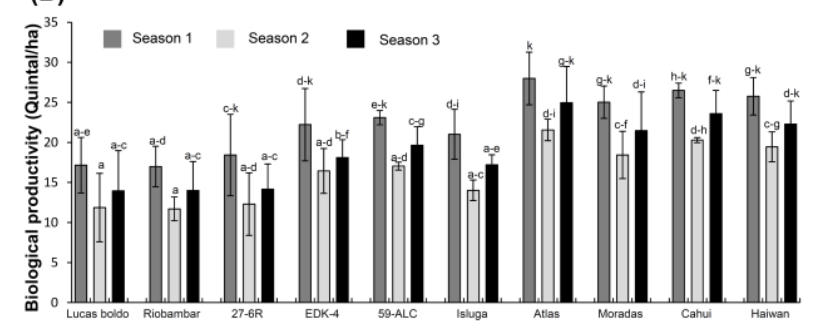

Fig 5. Estimation of biological productivity (A) and practical productivity of ten quinoa accession varieties planted in three different seasons. Bars represent mean values $( \pm S D)$ of three independent tests. Different letters above bars indicate the statistically significant difference (ANOVA, $P<0.05$ ).

opposite, this number was approximately 21 branches, the lowest, observed in the Lucas boldo in season 2. We further measured the length of bunches from 10 quinoa accessions after 75 days of planting on Ferralsols in Dak Lak province. The result patterns showed in Figure $2 \mathrm{~B}$ were similar to data in the total main number bunches per quinoa plant. The quinoa accessions growth in season 1 had the bunch longer than those in other seasons. However, the Atlas showed the longest bunch length around $27 \mathrm{~cm}$, while the Lucas boldo showed the lowest bunch length that was around $18 \mathrm{~cm}$. Collectively, the Atlas exhibited as the best quinoa accession variety, which gained higher total number of the main bunch and the bunch was longer than other accession varieties follow the survey in Dak Lak province.

To further investigate the reproductive indexes, we measured the number of seeds and weight of grains. Therefore, 10 quinoa accession varieties in three seasons in the same Ferralsols condition were planted. The analysis was conducted using 75-day-quinoa plants. The results showed that there were no significantly difference among 10 quinoa varieties in each season (Fig. 3A) $(P<0.05)$ even though the quinoa accession grow showed a slightly higher number of seeds per bunch in season 1 than those in other seasons. This result suggested that the number of seeds in a bunch among ten quinoa accessions was not significantly affected by the seasonal factors.

It was well documented that measuring of the weight 1,000 grains is the most important determinant of quinoa yield (Nguyen et al., 2020). Therefore, we further investigated the weight of 1,000 quinoa grains. The results showed that there were no significant difference among 10 quinoa varieties in each season even though this index in season 1 showed slightly higher than those in other seasons (Fig. 3B) $(P<0.05)$. The results showed a lowest of 2.58 grams (in the 27-6R) to the highest of 3.21 grams (in the Atlas), which was significantly different at $(P<0.05)$. However, the Atlas did not show any significant statistically difference compared to Leucan Boldo, Riobamba, 27-6R, and Isluga varieties. Taken together, our data indicated that, season 1 lasts from January to April (whole dry season) is the most suitable period for quinoa accessions reproductive. Therefore, the quinoa accessions may grow better in the dry season.

\section{Analysis of seed components constituting the yield of quinoa accessions}

Quinoa is a food plant with high nutritional value. The protein content in quinoa seed is about $15-21 \%$, making it one of the very few seeds with enough amino acids necessary for human (FAO, 2013). Each quinoa variety has different total protein and starch contents, which were largely determined by the variety's genetic characteristics (Graf et al., 2016; Wu et al., 2017). The results of the total protein content of quinoa accession varieties grown on Ferralsols in Dak Lak province were shown in Figure 4A. Generally, the total protein content of each accession variety was similar among the three seasons. Interestingly, the Atlas showed significantly higher total protein content than other accession varieties $(p<0.05)$. On the other hand, analysis of the starch content showed similar results among 10 quinoa accession varieties in three different seasons (Fig. 4B) $(p<0.05)$. Taken together, these data indicated that the quinoa accessions starch contents might not largely depend on genetic characteristics and seasonal factors. Instead, total protein content may be affected by genetic characteristics and seasonal factors.

\section{Analysis of biological and practical yields}

The yield of quinoa is the final result of growth and development of this crop. The yield depends on the genetic characteristics of each breed in similar climate, soil type and cultivation techniques (Altieri et al., 2015; Raza et al., 2019). This is also the most important criterion that farmers, researchers, and businesses are interested in choosing a variety for cultivation.

The results of monitoring and estimation of biological yield of quinoa accession varieties are displayed in Figure 5A. The quinoa accession growth in season 1 showed a higher yield than that in other seasons. The Atlas showed similar biological yield in Moradas, Cahui, and Haiwan varieties but much higher than other varieties $(p<0.05)$. The biological yield of the Atlas 
in season 1 was 28 quintals per hectare, while this index was 11.8 quintals per hectare in the Lucas boldo in season 2 . Similarly, the results of average practical yield indicators of the experimental plots showed quite differences between quinoa accession varieties (Fig. 5B). The quinoa accession growth in season 1 showed a higher yield than that in other seasons. The Atlas showed similar and not much significant higher biological yield in comparison to Moradas, Cahui, and Haiwan varieties but much higher than the other varieties $(P<0.05)$. Whereby, the experimental yield of Atlas variety in season 1 was 22.2 quintals per hectare, while this index was 7.9 quintals per hectare in the Lucas boldo in season 2 . These results were much lower than the practical yield. The difference might have been caused by cultivation techniques and natural conditions.

\section{Materials and methods}

\section{Plant materials}

Ten selected quinoa accession varieties used in the study were supplied by Professor Daniel Betero, University of Buenos Aires, Argentina (Table 2).

\section{Time and place of the study}

The experiments were carried out in three seasons of 2020. Season 1: from January to April 2020 (whole dry season). Season 2: from May to August 2020 (Entire rainy season). Season 3: from September to December 2020 (half rainy season and half-dry season). In the research location, information of monthly average climatic data on temperature, rainfall, and relative humidity are shown in Table 1.

All of the field experiments were conducted on Ferralsols in Buon Ma Thuot city, Dak Lak province of Vietnam

\section{Experimental arrangement method}

Field experiments were conducted based on the Randomized Complete Block Design (RCBD). Each experiment was repeated three times. The experimental plot area was $14 \mathrm{~m}^{2},(5 \mathrm{~m} \times 2.8$ $\mathrm{m}$ ) and the distance each repeating was $1 \mathrm{~m}$. A total of 30 test plots $\left(420 \mathrm{~m}^{2}\right)$ excluding paths and protective fences (barrier) on the fertilizer base for $1 \mathrm{ha} /$ crop was $1,000 \mathrm{~kg}$ of microbiological organic fertilizer $+500 \mathrm{~kg}$ of lime powder +90 kg N +60 kg $\mathrm{P}_{2} \mathrm{O}_{5}+60 \mathrm{~kg} \mathrm{~K} 2 \mathrm{O}$ density of 100,000 plants/ ha (row to row was $50 \mathrm{~cm}$; plant to plant was $20 \mathrm{~cm}$ ) (Dinh et al., 2014).

\section{Tracking criteria}

Agronomical factors: the plant height, branch number, the total number of the main bunch, length of bunch, and number of grains per bunch were analyzed 75 days after planting (the end of the growing period and beginning of the seed development). The grains weight, protein and starch contents were analyzed after harvest (90 days after planting)

Theoretical productivity (biological productivity) (quintal per ha per crop) $=$ number of bunches per plant $\times$ number of seeds per bunch $\times$ weight of 1,000 seeds $\times$ number of alive plants (plants per ha) / 10,000.

Production capacity (practical productivity) (quintal per ha per crop) $=$ Weight of quinoa seeds harvested per experimental plot $(\mathrm{kg}) \times$ total number of plots per ha)/10,000.

\section{Method of determining total protein content}

The total protein content (\%) was determined followed the Kjeldahl method as described by Reguera et al. (2018).

The protein content is calculated by the formula $X(\%)=a * 0.00142 * b * V^{*} 100 *\left(v^{*} c\right)^{-1}$
Therein

a $(\mathrm{ml})$ : Amount of $\mathrm{H}_{2} \mathrm{SO}_{4}$ used for titration after subtracting from the control flask 0.00142: $\mathrm{mg}$ of nitrogen equivalent to $1 \mathrm{ml}$ of $0.1 \mathrm{~N} \mathrm{H}_{2} \mathrm{SO}_{4}$ $\mathrm{V}(\mathrm{ml}): \mathrm{ml}$ of diluted sample solution $(50 \mathrm{ml})$ $\mathrm{v}(\mathrm{ml}): \mathrm{ml}$ of ammonia distillation sample solution $(20 \mathrm{ml})$ c (g): Weight of sample to be analyzed b: Nitrogen transfer factor $(b=6.25)$

\section{Method of determining the starch content}

Use the method of Bertrand described by Kumar et al. 2014 to determine this amount of reducing sugars.

The starch content is calculated in $\%$ by the formula

$\mathrm{X}=(\mathrm{a}-\mathrm{b}) \times 0.9(\%)$

Therein

a: reducing sugar content after hydrolysis (\%)

b: general sugar content in glucose $(\%)$

0.9: ratio of conversion from glucose value to starch

\section{Statistical analysis}

Statistical analyses were performed using Excel program (2016) and SPSS 23.0 software (IBM Co, Armonk, NY), which included one-way analysis of variance (ANOVA) and Duncan's multiplerange test. Different letters indicate statistically significant differences at $p<0.05$ by Duncan's multiple-range test. Monitoring all studied indicators was carried out according to the document "Description of Quinoa and wild type" (FAO, 2013).

\section{Conclusion}

Quinoa accessions adapted well to Basalt Red soil (Ferralsols) in Dak Lak province, the Central highland of Vietnam, with better planted in the dry season. Among 10 quinoa accession varieties, Atlas showed the highest-quality indexes including agronomical traits and practical productivity follow by the Moradas, Cahui, and Haiwan varieties.

\section{Acknowledgements}

We thank Prof. Dr. Daniel Bertero from University of Buenos Aries, Argentina to supply quinoa accessions seeds. We thank the financial support from the Ministry of Science and Technology of Vietnam for the Project "Selection and development of quinoa products for suitable ecological regions in Vietnam".

\section{Conflict of interest}

The authors declare that there are no conflicts of interest.

\section{Source of funding}

This study is funded by the Ministry of Science and Technology of Vietnam

\section{Author contributions}

NV Minh and TV Nguyen designed the experiments; NV Minh performed the experiments and interpreted the data; TV Nguyen wrote the manuscript.

\section{References}

ADB (Asian Development Bank) (2013) Viet Nam: Environment and Climate Change Assessment. 
https://www.adb.org/documents/viet-nam-environment-andclimate-change-assessment.

Aguilar PC, Cutipa Z, Machaca E, Lopez M, Jacobsen SE (2003) Variation of proline content of quinoa (Chenopodium quinoa Willd.) in high beds (Waru waru). Food Rev Int. 19: 121-127.

Altieri MA, Nicholls $\mathrm{Cl}$, Henao A, et al. (2015) Agroecology and the design of climate change-resilient farming systems. Agron Sustain Dev. 35: 869-890.

Bertero HD, Vega AJDL, Correa G, Jacobsen SE, Mujica A (2004) Genotype and genotype- by-environment interaction effects for grain yield and grain size of quinoa (Chenopodium quinoa Willd.) as revealed by pattern analysis of international multienvironment trials. Field Crop Res. 89: 299-318.

Dinh TH, Nguyen TC, Nguyen VL (2015) Effect of nitrogen fertilization on growth and yield of some imported quinoa varieties. J Sci Dev. 13: 173-182.

FAO - Food Agriculture Organization of the United Nations (2013) International year of quinoa. http://www.fao.org/quinoa-2013/en.

García M, Roa D, Stechauner R, Molano F, Bazile D, Plazas N (2020) Effect of temperature on the growth and development of quinoa plants (Chenopodium quinoa Willd.): a review on a global scale. Sylwan 165(5): 23.

Graf BL, Rojo LE, Delatorre-Herrera J, Poulev A, Calfio C, Raskin I (2016) Phytoecdysteroids and flavonoid glycosides among Chilean and commercial sources of Chenopodium quinoa: variation and correlation to physico-chemical characteristics. J Sci Food Agri. 96 (2): 633-643.

Granado-Rodríguez S, Aparicio N, Matías J, et al. (2021) Studying the impact of different field environmental conditions on seed quality of quinoa: the case of three different years changing seed nutritional traits in southern Europe. Front Plant Sci. 12: 649132.

Kumar CSC, Mythily R, Venkatachalapathy R, Chandraju S (2014) Bio mimic conversion of Maida (poly-saccharides) to reducing sugars by acid hydrolysis and its estimation using standard method. Int Food Res J. 21(2): 523-526.

Hinojosa L, González JA, Barrios-Masias FH, Fuentes F, Murphy KM (2018) Quinoa abiotic stress responses: A Review. Plants 7(4):106.
Lyakhovkin AG, Tran DL (1994) New and less popular crops in Vietnam. Agriculture Publisher, Hanoi, Vietnam.

Raza A, Razzaq A, Mehmood SS, Zou X, Zhang X, Lv Y, Xu J (2019) Impact of climate change on crops adaptation and strategies to tackle its outcome: A Review. Plants 8(2): 34.

Reguera M, Conesa CM, Gil-Gómez A, et al. (2018) The impact of different agro ecological conditions on the nutritional composition of quinoa seeds. Peer J. 6:e4442

Ruiz-Carrasco K, Antognoni F, Coulibaly AK, et al. (2011) Variation in salinity tolerance of four lowland genotypes of quinoa (Chenopodium quinoa Willd.) as assessed by growth, physiological traits, and sodium transporter gene expression. Plant Physiol. Biochem. 49: 1333-1341.

Tran TD, Vu THT (2013) Impact of climate change on growth and development in Vietnam and some policy implications. J Eco Dev. 193:15-22.

Trinh, ND (2001) Research and development of golden seed (Chenopodium quinoa Willd.) in the North of Vietnam (Doctoral thesis). Agricultural Academy Publisher, Hanoi, Vietnam.

Nguyen VM, Hoang DT, Nguyen VL, Nguyen VL (2020) Effects of plant density on growth, yield and seed quality of quinoa genotypes under rain-fed conditions on red basalt soil regions. Aust J Crop Sci. 14(12):1977-1982.

Nguyen VM, VL Nguyen (2019) Analysis some imported quinoa cultivar (Chenopodium quinoa Willd.) Planted on basalt soil in dry season in Dak Lak province. J HUAF. 3:52-60.

Van Wambeke A (1992) Soils of the Tropics-Properties and Appraisal. McGraw Hill Inc., New York.

Vu TH, Vu TN (1993) HV1 varieties and planting techniques. J Agri Rural Dev.6: 294-299.

Wang N, Wang F, Shock CC, Meng C, Qiao L (2020) Effects of management practices on quinoa growth, seed yield, and quality. Agronomy 10(3): 445.

Wu G, Morris CF, Murphy KM (2017) Quinoa starch characteristics and their correlations with the texture profile analysis (TPA) of cooked quinoa. J Food Sci. 82(10):23872395. 